\title{
A touch of the vapours...
}

\author{
Lesley Smith
}

Tutbury Castle, Tutbury, UK

Correspondence to

Ms Lesley Smith, Tutbury Castle, Tutbury, Staffordshire

DE13 9JF, UK;

info@tutburycastle.com

Received 9 May 2011

Accepted 14 May 2011
Hysteria through the ages

The medieval period through to early modern times in England has left us a legacy of a large number of medical records related to gynaecological issues and what appear to be the symptoms of women suffering with hormonal imbalances. Among those records is evidence of how society and the medical profession of the day diagnosed and treated hysteria.

Hysteria caused a great deal of interest and alarm. This is hardly surprising, as the sight of a woman screaming and crying uncontrollably as well as babbling incoherently before fainting was very dramatic and there are a number of historical references to such episodes. For some onlookers, particularly in the 15th, 16th and 17th centuries, the woman may have appeared to be in the grip of an evil spirit, which may mean she might not have been treated sympathetically by a society that believed in demon possession, not to mention fairies. Fortunately, it seems most physicians and midwives were aware of hysteria, although some of the reasoning as to why and how this happened meant treatments could be very uncomfortable indeed.

There are blanket phrases that appear regularly in textbooks and physicians' notes such as "fits of the mother", "suffocation of the womb" and "strangulation of the Mother"; the latter talks of strangulation of the womb itself as "the Mother" is a common description of the womb. It seems the range of medical conditions was so overwhelming that physicians of the period resorted to using general terms.

Internal vapours

By the 15th century, the idea of the body not properly releasing any matter that should be released was at the root of the belief in attempting to understand hysteria. Stale, and therefore toxic, menstrual blood and/or "seed" were thought by many physicians to be the primary cause of the condition. The corrupt women's seed diagnosis comes from the apparent general view that conception was caused by dual ejaculation and therefore wasted seeds grew corrupt and sent up "filthy vapours to the brain". Widows, no longer able to enjoy regular intercourse, were thought to be particularly at risk. Also, young women or any "maid" unmarried and therefore unable to release their seeds were most likely to suffer the vapours. Men were believed to be free of this condition because the nature of their bodies meant their seed could be lost unwillingly in sleep if overcharged and also because men, unlike women, engaged in "pollution". "Pollution" was one term used for masturbation. For the purposes of this article, the fact that our ancestors almost always misjudged women's sexual activity is irrelevant. What they believed is how medical practice and treatments were developed.

The whole of society knew that eggs from any creature (e.g. birds or snakes) would eventually become rotten and smell. Foul smells were believed to be closely aligned to disturbing the humours of the body and therefore caused illness.

The internal vapour theory is an odd one to the modern observer, not least because it is known how highly educated medieval and early modern physicians were. However, knowledge of anatomy was confused, and the interpretation of what they were looking at when they did see inside the human body was subject to misunderstanding.

\section{Tumours and cysts}

These vapour ideas were reinforced as autopsies, which were performed on a regular basis from the 17th century onwards, revealed what appeared to the doctors to be "women's stones" or seed held in the body. The vapour released from what were obviously tumours and cysts of various forms were, not unexpectedly, foul of smell. Jane Sharp, a famous midwife of the time, details in her work The Midwives Book first published in 1671 , what one might see in the womb area of a dead woman as "like bladders full of a clear watery humour", 
and she goes on to state that the smell from them internally caused "the stringing of the mother". For those wondering how people might have believed the smell arose in their bodies without the cysts being ruptured, can be found the description of putrefied blood vapours that passed through the arteries of the neck and entered into the two parts of the "infundibulum" into the frontal lobes of the head causing the woman to feel choking and fall down in a swoon.

\section{Depression}

Other physicians give examples of what appears to be depression or premenstrual tension, with women described as struck with terrible melancholy and fear. Interestingly, depression was seen to be linked with the menstrual cycle and the menopause. In the 16th century, the physician Barrough wrote about female patients afflicted with "sorrow and sadness and dejection of the minde". More evidence as to why it was believed that every effort should be made to ease body and mind with a healthy menstrual cycle and sex life.

\section{Coupling and conception}

Retention of the menses was not only of grave concern because of the risk of ill health but also because of its link with conception. Much discussion can be found in books and papers of the time as the medical profession produced a range of favoured treatments. Bleeding was a popular choice for centuries with the use of a bloodletting knife and bowl or leeches. The word 'leech' is an Anglo-Saxon word meaning 'doctor', and it seems likely the creature was named after the profession as they were thought to do so much good. Cupping was used as well as a wide range of pharmacology, some of which was toxic and possibly lethal.

Some physicians such as Sadler believed that intercourse would cure many ills in a woman and was the ultimate solution for releasing retained menses or corrupt seed. Husbands were recommended to paint the top of their yard (penis) with sweet almond oil and gillyflower. The womb was thought to be attracted and open up to sweet smells and close down or even wander away from foul ones. Doctors urged that sexual intercourse should then take place, which would enable the woman to let the content of the womb be released. No doubt the spasm of orgasm was thought to be helpful.

Midwives were invited to help patients if a husband was not available by anointing their fingers in scented oil and moving their fingers in and out of the woman's vagina, "rubbing it long and easily" until the foul humours were expelled. This sexual health service raised quite a few eyebrows in the medical profession in its day and I apologise for having mentioned this process in a previous article about the work of midwives but I do feel it is worth considering again if not only for its astonishment value.

The idea of the marriage bed solving any number of gynaecological difficulties is supported by the memory of many of us as young women being told by older female relatives that all would be well when we got married. Even acne, if I remember rightly.

\section{Timeless hysteria remedy}

Finally, the treatment for hysteria, which has a very modern note about it, is to hold a pot of strong-smelling liquid under the nose of the patient in order to drive the evil humours back down the body, which will then bring the patient back to consciousness. Smoke from burnt frogs or feathers and pots of strong urine are suggested; but right up until the 1950s, sal volatile (smelling salts) had the same effect for the same condition.

\section{Future articles}

The next article in this series will consider the "AngloSaxon Leech Book".

\section{About the author}

Lesley Smith is currently a postgraduate student in the Centre for the History of Medicine of the University of Birmingham, where she is developing a $\mathrm{PhD}$ in obstetrics and gynaecology in early modern Britain. She holds an honorary degree for 'services to history'. She makes 200-300 public appearances a year and also works as a TV historian in the UK and abroad including the USA. Lesley is also Curator of Tutbury Castle in Staffordshire, and is a member of the Society of Apothecaries of London and the Society of Medical Writers. She has recently been appointed a Fellow of the Society of Antiquaries of Scotland.

Acknowledgement The author would like to thank Dr G Williams, British Museum, London, UK for his help and advice.

\section{Competing interests None.}

Provenance and peer review Commissioned; internally peer reviewed.

\section{Bibliography}

1 Sharp J. The Midwives Book: Or the Whole Art of Midwifery Discovered. New York, NY: Oxford University Press, 1999. (Original edition published 1671.)

2 Eccles A. Obstetrics and Gynaecology in Tudor and Stuart England. London, UK: Croom Helm, 1982.

3 Sloan AW. English Medicine in the Seventeenth Century. Durham, UK: Academic Press, 1996.

4 Pechey J. A General Treatise of the Diseases of Maids, Big-bellied Women, Childbed Women \& Widow. (Original edition published 1698; there is a reproduction of the original in the British Library.)

5 Pechey J. The Compleat Midwife's Practice Enlarged in the Most Weighty and High Concernments of the Birth of Man: Containing a Perfect Directory or Rules for Midwives and Nurses. (Original edition published 1698, publisher unknown.)

6 Barrough P. The Method of Physick. (Original edition published 1624, publisher unknown.)

7 Culpepper N. Directory for Midwives. (Original edition published 1651, publisher unknown.) 